\title{
Information Technology and decision support tools for stakeholder-driven river basin salinity management
}

Nigel W.T. Quinn, PhD, PE, D.WRE

Berkeley National Laboratory

nwquinn@lbl.gov

\author{
Daniel B. Cozad \\ Central Valley Salinity Coalition \\ dcozad@intpln.com
}

\author{
Gene Lee \\ US Bureau of Reclamation \\ glee@usbr.gov
}

\begin{abstract}
Innovative strategies for effective basin-scale salinity management have been developed in the Hunter River Basin of Australia and more recently in the San Joaquin River Basin of California. In both instances web-based stakeholder information dissemination has been a key to achieving a high level of stakeholder involvement and the formulation of effective decision support salinity management tools. A common element to implementation of salinity management strategies in both river basins has been the concept of river assimilative capacity for controlling export salt loading and the potential for trading of the right to discharge salt load to the river - the Hunter River in Australia and the San Joaquin River in California. Both rivers provide basin drainage and the means of exporting salt to the ocean. The paper compares and contrasts the use of monitoring, modeling and information dissemination in the two basins to achieve environmental compliance and sustain irrigated agriculture in an equitable and socially and politically acceptable manner.
\end{abstract}

\section{Introduction}

Salinity management is an important sustainability issue in arid river basins around the world - especially those that support an agricultural sector reliant on irrigated agriculture [1]. The Hunter River Basin of Australia and the San Joaquin Basin of California are two examples of large river basins where information technology, monitoring and modeling are being used in support of regulatory Basin Plans for salt management.

Salinity is defined as the concentration of dissolved salts in a water body. Salts degrade water bodies through such activities as domestic use, irrigated agriculture, confined animal waste practices, and other human, industrial, and natural processes. Degradation of surface water supplies can limit the use of water for agricultural, industrial, municipal, and other purposes.
Certain salt sensitive agricultural crops experience progressive yield declines when the salt concentration of applied irrigation water exceeds a certain threshold resulting in economic losses to the agricultural sector.

\subsection{Geography}

The Hunter River Basin is the largest coastal catchment in the State of New South Wales, Australia - covering approximately 22,000 square kilometers and is drained by the Hunter River. The San Joaquin River Basin in California is about twice the size covering 40,500 square kilometers and is drained by the San Joaquin River. Both drainage basins are fed by a number of large tributary rivers. Agricultural production in both areas is measured in billions of dollars to the local economy. A range of agricultural activities are contained within the Hunter River Basin including wineries, dairying, vegetables, fodder, beef and horse breeding. The Basin also contains more than 20 of the world's largest coal mines and power generating stations. Salt occurs naturally in many rocks and native soils of the region - it is leached into groundwater and nearby rivers through activities such as irrigation and coal mine pump drainage. Electricity generation consumptively uses large volumes of river water increasing the concentration of the saline river water.

The San Joaquin Basin can be divided into two subbasins east and west of the San Joaquin River that have radically different native soils and hydrology. All rivers to the east of the San Joaquin River originate in the Sierra Nevada mountains and contain water of high quality derived from the mountain snowpack. Soils derived from the granitic Sierra Nevada alluvium are sandy in texture and contain few native salts. Soils on the west-side of the River, on the other hand, are derived from marine sediments, contain high levels of native salts and are irrigated with water pumped and conveyed south from the San Francisco Bay Delta. 
In both Hunter and San Joaquin River Basins groundwater pumping can be used to offset surface water deliveries. Most surface water has a salinity that ranges from 300- $600 \mathrm{uS} / \mathrm{cm}$ EC although specific ions such as boron dictate the salt tolerance of locally grown agricultural crops. Irrigated agriculture has been practiced in both Basins for about about 100 years, and has led to a degradation of groundwater quality.

\subsection{Basin Planning}

Water rights are assigned and adjudicated by the state government in both River Basins and both are regulated by Basin Plans which set numerical limits on salinity at a downstream compliance monitoring station. In the Hunter River Basin the State has set a seasonal limit of $900 \mathrm{uS} / \mathrm{cm}$ which must be attained $95 \%$ of the time at a compliance monitoring station, located at Singleton, at the end of the lower River. There is, however, no regulatory agency in the State that enforces the limit - rather compliance is achieved by internal management and enforcement. In contrast, in the San Joaquin River Basin the Basin Plan has established numerical limits of $700 \mathrm{uS} / \mathrm{cm}$ for the irrigation season (April - August) and 1,000 uS/cm for the non-irrigation season September - March). These limits have been use to develop a Total Maximum Daily Load (TMDL) allocation for the Basin which are to be enforced through the assignment of Waste Discharge Requirements (WDR) for each entity discharging salt into the River. A permit from the State is required for discharge - this permit authorizes permissible monthly and annual salt loads and is the primary mechanism of regulation.

\section{Appropriate use of Information Technology Resources}

In the United States major many basin-scale water quality management regulatory initiatives follow the EPA-mandated TMDL approach - which provides a methodology for developing numerical load limits for each discharger based on a simulation model of the basin or watershed [2][3]. Modeling tools such as BASINS [4][5], WARMF (Watershed Analysis Risk Management Framework) and SWAT (Soil and Water Assessment Tool) http://www.brc.tamus.edu/swat/ are among the most popular to guide TMDL development in river basins. Once a model application for the project area has been established and the base load allocations determined - the TMDL is approved through a public involvement process. A compliance monitoring system is typically established that provides regulators with the data needed to assess adherence to the load limits of the TMDL and that gives stakeholders a means of gauging their success in managing salt load discharge to the River.

The TMDL approach has been successfully applied in watersheds throughout the United States - however strict adherence to EPA guidelines for TMDL development can preclude consideration of more straight-forward and cost-effective solutions. A more creative use of information technology resources can sometimes achieve the same environmental goal as the more doctrinaire TMDL solution at lower monetary and regulatory cost. In this paper we describe a variant to the standard TMDL protocol to address salt management in the San Joaquin Basin of California. The theme of appropriate use of IT resources is examined by contrasting an innovative application of salinity management in the Hunter River Basin of Australia with salinity management in the San Joaquin Basin. The different technical approaches taken in these case studies can be ascribed, in part, to the social and political contexts for the Basin planning process. These factors also affect the cost-effectiveness of each salinity management strategy.

\section{Use of Information Technology for salt load regulation in the Hunter River Basin}

Salinity management within the Hunter River Basin of the State of New South Wales (Fig 1) is administered as a market-based salt load licensing and trading system by the Hunter-Central Rivers Catchment Management Authority. This system allows parties to buy and sell permits for salt load export or credits for reductions in salt load export (Fig 2). This system also sets limits on salt loads emitted by holders of environment protection licenses and links licensing fees to salt load export. (http://www.environment.nsw. gov.au/licensing/hrsts/allocating.htm). The website is used to explain the elements of the licensing program, the basis for allocation of permissible salt loads and the rules for salt load trading. The licensing system combines the strengths of several water quality regulatory instruments to achieve optimal environmental and economic outcomes. Features of the system include: (a) sets a clear set of minimum standards for environmental performance; (b) incorporates incentives for salt load reduction; (c) gives licensees the flexibility to implement innovative cost-effective salt load abatement methods; (d) provides the infrastructure for salt load trading and the ability to calculate export salt load using a defined Load Calculation Protocol.; (e) enables the long-term tracking of salt load reductions; (f) requires each licensee to submit an annual return at the end of each 
12-month license fee period. This return is made using a simple web-based license fee calculator which enables and encourages stakeholder forecasting of future fees under various pollution reduction scenarios

Under the Hunter River salinity management system stakeholders that emit pollutants must obtain sufficient tradable units to compensate for their salinity load export. Stakeholders that reduce salt loads may have surplus salt load credits that they can sell to others that find emission reduction more expensive or difficult.

\subsection{Monitoring}

Real-time flow and water quality monitoring networks have been developed to report flow and water quality data information from key riverine stations within the Basin. This network also reports data from weather stations and both inflow and outflow to the major reservoirs within Basin. These data are important for planning seasonal water allocations, planning releases from dam storage and both water and salt accounting. This network of stations is used occasionally for emergency response situations in the Hunter River and its tributaries.

\subsection{Modeling}

Basin-scale simulation models have been developed by the State of New South Wales for water and salinity load management within the Hunter River Basin. These models typically provide the gross Basin hydrology based on rainfall-runoff hydrology, river diversions and accretions and evaporation for a climate record of more than 100 years. Output from the basinscale model is passed to daily operations model that simulates daily flows and salt loads in the River. Databases have been developed which stores model output data for a wide range of management scenarios - these outputs can be used to guide real-time decision making for water and salinity in the Basin.

\subsection{Information dissemination}

The State of New South Wales has established Catchment Management Authorities (CMA's) to ensure that regional communities have a voice in how natural resources are managed within their catchments. The Hunter-Central Rivers CMA has a Waterwatch Program, http://www.hcr.cma.nsw.gov.au/waterwatch. php3 which is part of a national program of the same name, with outreach to schools and local communities to perform flow and water quality testing and establish new monitoring sites. Among this program's goals are community involvement in identifying and assessing the location and relative magnitude of stream salinity sources and promotion of community partnerships in developing appropriate salinity management actions. The program provides free training and equipment to test salinity levels in local creeks and waterways. It also provides a mechanism for disseminating expert technical advice on salinity remediation issues and for alerting stakeholders to funding opportunities. A public, on-line database has been developed by the State, allowing the Waterwatch website to upload and view their data as well as data collected throughout the catchment.

\section{Use of Information Technology for salt load regulation in the San Joaquin River Basin}

The most striking differences between the California and Australian examples of information technology support for salinity management is the greater emphasis on regulation and police power in the California case and the high level of community outreach and public involvement in the Australian example. In an attempt at conformity the California TMDL approach can result in suboptimal resource management outcomes. Another significant difference is the role of government and the financing of these activities. Federal spending to improve salinity management within the Province of New South Wales is estimated at $\$ 10-12$ billion (Aus) over the next 10 years. In contrast the costs of TMDL compliance in California are mostly borne by the State and passed to stakeholders through permitting and forced compliance with Basin Plan monitoring requirements. State agency grants and competitive research funding programs are available but these do not come close to matching the financial resources devoted to salinity management in Australia.

The TMDL is intended to identify, quantify and help control sources of pollution that affect attainment of water quality objectives and full protection of identified beneficial uses of water. The TMDL includes both point and non-point sources of salt load. Point sources of salinity, such as discharges from wastewater treatment systems, are regulated using Waste Load Allocations (WLA). These WLA's are typically concentration based and allow the entities regulated to enter into a marketplace with other regulated entities to trade their allocations. Non-point sources of salinity (LA) are not typically amenable to the establishment of fixed monthly or seasonal salt load allocations because of the diffuse nature of these 
non-point source loads in the watershed which makes it difficult to assign responsibility, the technical challenges of monitoring individual discharge points and the high seasonal variation in export flows and salt loads. Base salt load allocations (LC) are made to account for the variable assimilative capacity for salt within the San Joaquin River - these are calculated based on the lowest anticipated flow condition in the River and the River's assimilative capacity (LC) for salt load during these episodes. Point source (WLA's), background salt loading and salt loads contained in groundwater return flows to the River are subtracted from the total assimilative capacity of the River to determine the salt load allocation to all non-point sources. A margin of safety is typically set at $15-20 \%$ of the total salt load and takes account of the hydrologic variability of the system and the technical inability to use $100 \%$ of the assimilative capacity of the River, even under near-perfect management.

The resulting TMDL salt load allocations provide almost zero salt load discharge during the irrigation season when irrigation water deliveries and drainage return flows are highest. The salinity TMDL was amended for the San Joaquin Basin is unique to permit an additional "real-time" load allocation that supercedes the conservative base non-point source load allocation (LA), provided that a "real-time salinity management program" is implemented in the Basin. The core requirements of this program include : the development of a sensor network to perform real-time monitoring of flow and salinity data for stakeholders from contributing watersheds; a data dissemination system for effective sharing of data among basin stakeholders to allow forecasting of River assimilative capacity; formation of an institution with regional authority to administer the system and ensure compliance with downstream salinity objectives; and sanctioning by the State Regional Water Quality Control Board. The impact of this additional real-time salt load allocation would be to permit significantly larger export of salt load from the watershed - helping to overcome salt build-up within the shallow groundwater system which would ultimately degrade the groundwater resource within the Basin.

\subsection{Monitoring}

Continuous flow and electrical conductivity sensors have been deployed at key river and tributary monitoring stations and have been connected within telemetered networks - all reporting to the web. Flow sensing technologies range in complexity from simple stage measurements that convert to flow through rating tables to acoustic Doppler sensors that measure stage and velocity directly to compute discharge. Continuously recording electrical conductivity sensors range from simple electrodes that are part of a Wheatstone network to solid-state sondes that are capable of performing temperature corrections and calibration internally. Telemetry systems in use include phone lines, CDMA (code division multiple access) cellular modems, satellite modems and GOES (geostationary operational environmental satellite) radios, which report to the orbiting satellite. A recent innovation designed to simplify the development of sensor networks has been the YSI-EcoNet (Yellow Springs International- http://www.ysi.com ) technology which integrates sensor hardware (acoustic flow probes, pressure and water quality sondes) and dataloggers with software that perform local data storage, telemetry and visualization. YSI-EcoNet comprises a mesh of Data Nodes (radio telemetry sites) and Access Nodes (CDMA cell phone telemetry sites). Each Access Node transmits logged data to a remote DataCenter from which the data is made accessible through the Internet. The commercial NIVIS Data Center maintains all data collected by the monitoring network at 15 minute intervals through a service contract with YSI Inc. The wireless mesh topology allows "point-to-point" connectivity and provides an ad hoc, multi-hop network configuration. The mesh network is self-organizing and self-healing - hence loss of one or more nodes does not necessarily affect its operation. This increases the overall reliability of the system by allowing a fast local response to critical events in the rare event of a communication problem. YSI-EcoNet has worked well by eliminating much of the tedium of downloading and processing environmental data.

The high cost of expanding the EcoNet-NIVIS system to accommodate an anticipated future monitoring network with 5-10 times the number of monitoring stations has necessitated investment in public domain tools and telemetry options that include GOES radio transmitters. A distributed data management architecture was sought that was easy to understand and inexpensive to implement as well as providing data providers with complete control over data sharing [6]. The CUAHSI (Consortium of Universities for the Advancement of Hydrologic Science Inc.) Hydrologic Information System (HIS) was chosen for this project.

The CUAHSI-HIS [7][8][9][10] provides a robust and well documented information management system framework that allows easy access and sharing of data among data providers. The system is built upon interoperable components that are connected to the 
web using the SOAP (Simple Object Access Protocol) services-oriented architecture. SOAP is a standard set of protocols established by the World Wide Web Consortium that allow one computer to request services of another. The HIS architecture provides a number of WaterOneFlow web services - these supply access to repositories of observation data locally-stored in ODM instances or in public agency databases. Another unique feature of the HIS is the WaterML language, an XML based language developed for use by web services to transmit water data in a standardized format. The HIS requires a centralized metadata catalog and registry of web services maintained on a central server at the University of Texas. The distributed web data services model that CUAHSI-HIS provides was considered superior to the concept of a single data server given the desire of stakeholders to have complete control of and access to their own data. This also helps to ensure that adequate quality assurance is performed before data is shared with the public.

\subsection{Modeling}

Connectivity between monitoring station data and simulation models, used in salt load forecasting, will be accomplished through implementation of the CUAHSI-HIS. The goal is to allow automated daily updating of model data files from the HIS database allowing daily forecasts of San Joaquin River flow and salinity to be made. The WARMF-SJR model is an application of the public domain WARMF model code [11][12] (Fig. 3). The model and its complete documentation can be downloaded from the federal EPA website (www.epa.gov/athens/wwqtsc/html/ warmf.html) or by downloading from an FTP site. WARMF-SJR divides the river basin into a number of smaller watersheds based on surface drainage patterns. Watersheds are further subdivided into a number of land uses and major crop groupings - soil layers help control the rate of water infiltration and simulate changes in the groundwater table. These compartments are linked to allow the water and its associated pollutants to be transported within the watershed. Physical and chemical transformations can take place in each compartment although in the current application salinity is treated as a conservative substance. The model performs mass balance and heat budget calculations to determine the dynamic changes in flow, temperature, and chemical constituent concentrations for all compartments simultaneously. WARMF-SJR is run using a daily time step to accurately capture the effect of changing flow conditions on salt transport within the catchment [13]. The model routes the point and nonpoint salt loads to calculate their concentrations in river segments. Simulated model results can be confirmed by data monitored at various stations. Such confirmation reduces the uncertainties of model predictions.

WARMF-SJR was designed as a decision support system for stakeholder process. It is transparent, because the graphical user interface allows any stakeholder to view its inputs, outputs, data sources, and calibration results. The consensus module contains a road map for stakeholders to learn about the behaviors of the watershed. The output provides the easy to understand GIS maps showing the bar charts of salt loads from various sub regions of the watershed. The output also provides source contributions to the pollution loads from various land use categories of urban, forest, wetlands, and farmlands. Scenarios can be created and run in WARMF-SJR to determine the effect of management alternatives. The changes in salt loads and resulting water quality can be compared among scenarios to guide the stakeholders toward an effective salinity management plan.

\subsection{Information dissemination}

Stakeholder involvement in the Hunter River Basin salinity management program is an exemplar of community outreach. Public involvement in salinity management has only recently been provided focus through the formation of the Central Valley Salinity Coalition (CVSC) www.cvsalinity.org and a number of standing committees known collectively as CVSALTS. More than a million dollars of seed funding for CVSALTS was provided by the State - a significant portion of the operating funds for this Coalition will be provided by stakeholders throughout the Central Valley of California. The San Joaquin Basin covers roughly one quarter of the surface area of the Central Valley Basin.

Activities of the CVSC since its formation in 2008 have included the formation of an executive and a number of standing committees dedicated to technical and economic issues and public education and outreach. A salinity leadership committee provides broad stakeholder representation and direction to CVSALTS. The primary activities of the Coalition are directed at developing a Basin Salinity Management Plan that achieves comprehensive salt balance in the region that is inclusive of all current and developing beneficial uses of water. The role of the technical committees is to ensure that the design of the final salinity management system is based on sound science and is well coordinated with other regulatory programs and emerging water resource management issues. The 
public education and outreach committees strive to achieve broad public understanding of the issues and engagement in public outreach activities. The CVSALTS website is the primary vehicle for communication to the public and contains news, meeting agendas and minutes, and background information on the Coalition and its activities. CVSALTS part-sponsored the development of a PBSdocumentary entitled "Salt of the Earth" which has been successful at raising awareness of salinity issues within the Central valley and recently won a writing Emmy award.

Integration of salinity monitoring, simulation modeling forecasting and information dissemination is a longer term goal of the CVSALTS program and will require a substantial investment of time and money to achieve.

\section{Discussion}

Salinity management is a centuries-old problem that has been the death knell of many sophisticated civilizations throughout the Centuries - perhaps the most famous being Mesopotamia (now in present Iraq). Information technology will play a critical role in helping to solve this problem because the problem cannot be solved with technology alone. It demands the active participation of the stakeholder population, water agency personnel and regulators. Basin Plans for modern-day management of salinity need to be based on good science, need to consider the availability of sensors capable of providing flow and salinity data in real-time and consider the capability of numerical simulation models that can produce reliable forecasts of river assimilative capacity for salt loading.

The New South Wales, Australia and California, USA examples described in this paper provide examples of two different paths to achieve Basin-wide salt balance. Although the Australian example in the Hunter River Basin is more mature and better funded than its American equivalent in the San Joaquin Basin it also demonstrates an Australian aptitude for community-based resource management that does not exist to the same extent in the USA. This may be in part due to the manner government is integrated with community services in the country and the adaptability of Australian institutions to changed circumstances. It is notable that the Hunter River Basin and the adjacent Murray Darling Basin have formulated their management responses to the salinity problem in different ways. In the Hunter River Basin the relatively small size of the Basin has allowed the development of a unique salt loading tracking and trading program that is easy of understand conceptually and lends itself to a simple daily salt load accounting system. The Murray Darling Basin is significantly larger in area and traverses three States. The solution is still based on an accounting schema but the emphasis is on salt load allocation between States and keeping the entire basin in Basin in an equitable manner. The final salt management system design in the San Joaquin Basin of California is still a work in progress with many of the tools in place but without integration. By being stakeholder rather than federally funded progress will be slower and the final outcome less certain.

\section{Conclusions}

The paper has described the roles of real-time monitoring, modeling and data dissemination using state-of-the art information technologies in the Hunter River Basin of Australia and the San Joaquin Basin of California. In both instances web-based stakeholder information dissemination has been a key to achieving a high level of stakeholder involvement and the formulation of effective decision support salinity management tools. A common element to implementation of salinity management strategies in both river basins has been the concept of river assimilative capacity for salt and the trading of the right to discharge salt load to the receiving water - the Hunter River Basin in Australia and the San Joaquin River in California - which provide basin drainage and salt export to the ocean. The success of the Hunter River Basin salinity management program can be partly attributed to the adaptability of the program to the local environment - a limitation of the TMDL approach mandated for pollutant load management in the US.

\section{Acknowledgments}

This work was supported by the US Bureau of Reclamation Science and Technology Program and the U.S. Department of Energy and LBNL under Contract No. DE-AC02-05CH11231

\section{References}

[1] National Research Council. 1989, Irrigation-induced water quality problems. What can be learned from the San Joaquin Valley experience. National Academy Press, p4. 
[2]Arnold, J. G., and N. Fohrer. 2005, SWAT2000: Current capabilities and research opportunities in applied watershed modeling. Hydrol. Process. 19(3): 563-572.

[3] Imhoff, J.C. 2003, Recent Comparison Studies to Assist in Selection of Advanced Modeling Tools for TMDL Development. WEF TMDL 2003, November 16-19, 2003. Chicago, Illinois.

[4] Lahlou, M, L. Shoemaker, S. Choudhury, R. Elmer., A. Hu, H. Manguerra, and A. Parker. 1998, Better Assessment Science Integrating Point and Nonpoint Sources. BASINS, Version 2.0 User's Manual. EPA-823-B-98-006. U.S. EPA, Washington, D.C. 65 p.

[5] USEPA .1995, Technical Guidance Manual for Developing Total Maximum Daily Loads, Book II: Streams and Rivers, Part 1: Biochemical Oxygen Demand/Dissolved Oxygen and Nutrients/Eutrophication. EPA 823-B-95-007, U.S. Environmental Protection, Office of Water, Washington, DC.

[6] Beran, B. and M. Piasecki, (2009), "Engineering new paths to water data," Computers \& Geosciences, 35(4): 753760, http://dx.doi.org/10.1016/j.cageo.2008.02.017.

[7] Horsburgh, J. S., D. G. Tarboton, D. R. Maidment and I. Zaslavsky, (2008), "A Relational Model for Environmental and Water Resources Data," Water Resour. Res., 44: W05406.

[8] Maidment, D.R., ed. (2008), CUAHSI Hydrologic Information System: Overview of Version 1.1, Consortium of Universities for the Advancement of Hydrologic Science, Inc, Washington, DC, 96p, http://his.cuahsi.org/documents /HISOverview.pdf.

[9] Tarboton, D.G., (2005), "Review of Proposed CUAHSI Hydrologic Information System Hydrologic Observations Data Model." Utah State University. May 5, 2005. http://www.engineering.usu.edu/dtarb/HydroObsDataModel Review.pdf.

[10] Zaslavsky, I., D. Valentine and T. Whiteaker, (2007), "CUAHSI WaterML," OGC 07-041r1, Open Geospatial Consortium Discussion Paper, http://portal.opengeospatial. org/files/?artifact_id=21743.

[11] Chen, C. W., J. Herr, L. Ziemelis, R. A. Goldstein, and L. Olmsted. (1999), Decision Support System for Total Maximum Daily Load. Journal of Environmental Engineering, ASCE, Vol. 125, No. 7, July 1999.

[12] Chen, C.W., J. Herr, and L. Weintraub (2004), Decision Support System for Stakeholder Involvement. Journal of Environmental Engineering, ASCE, Vol. 130, No. 6, June 2004.

[13] Quinn, N.W.T. and J. Karkoski, 1998, Real-time management of water quality in the San Joaquin River Basin,
California. American Water Resources Association, Vol. 34, No. 6. 


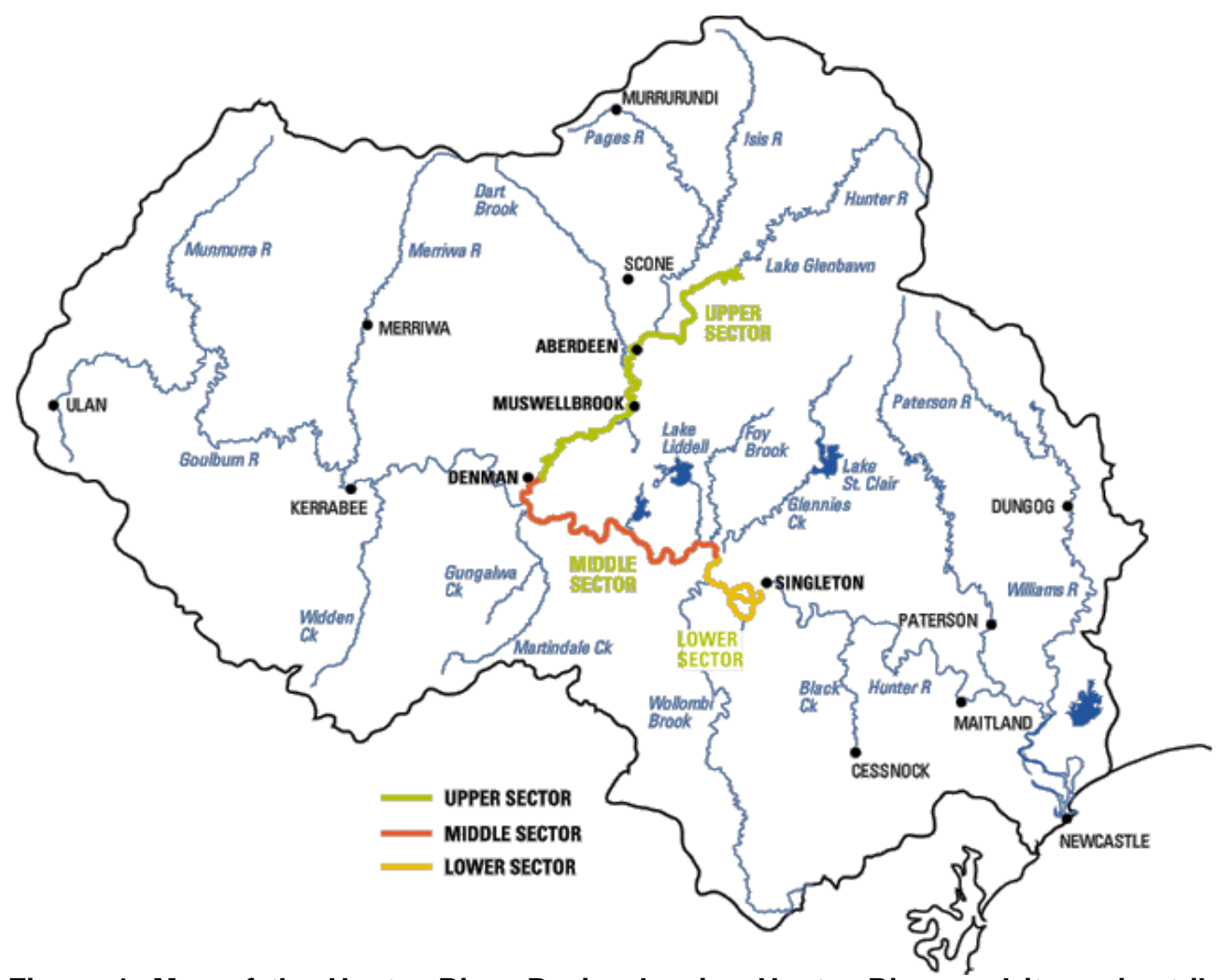

Figure 1. Map of the Hunter River Basin showing Hunter River and its major tributaries. The compliance monitoring station for salinity is located at Singleton where an EC of $900 \mathrm{uS} / \mathrm{cm}$ should be met $95 \%$ of the time. The Hunter River Basin salinity management project is one of the most innovative and successful projects of its type in the world. http://www.environment.nsw. gov.au/licensing/hrsts/allocating.htm

The river is divided into 'blocks'

The water in the river is nominally divided into numbered blocks. A block is a section of water that flows past Singleton in a day. So, block 2003-198 is the block of water that will flow past Singleton on the 198 th day of 2003 (17 July). This block of water will flow past other points on the river on different days.

For each block, the scheme operators continually monitor the flow level and the ambient salinity and then calculate how much salt (if any) can be added to the block (Total Allowable Discharge) so that salinity stays under the target.
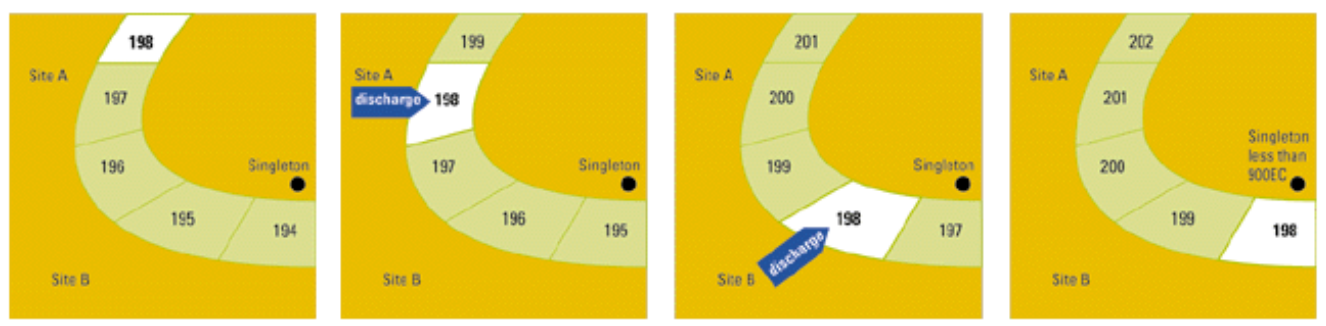

Figure 2. The Hunter River Basin salinity management project website explains the concept of salt load scheduling. The river is divided into numbered blocks - each representing a day's flow volume. Those with salt load export rights have the ability to allocate their salt load to one or more of these blocks, provided there is sufficient river assimilative capacity and their allocation falls within their allowable allocation http://www.environment.nsw.gov.au/licensing/hrsts/ allocating.htm 


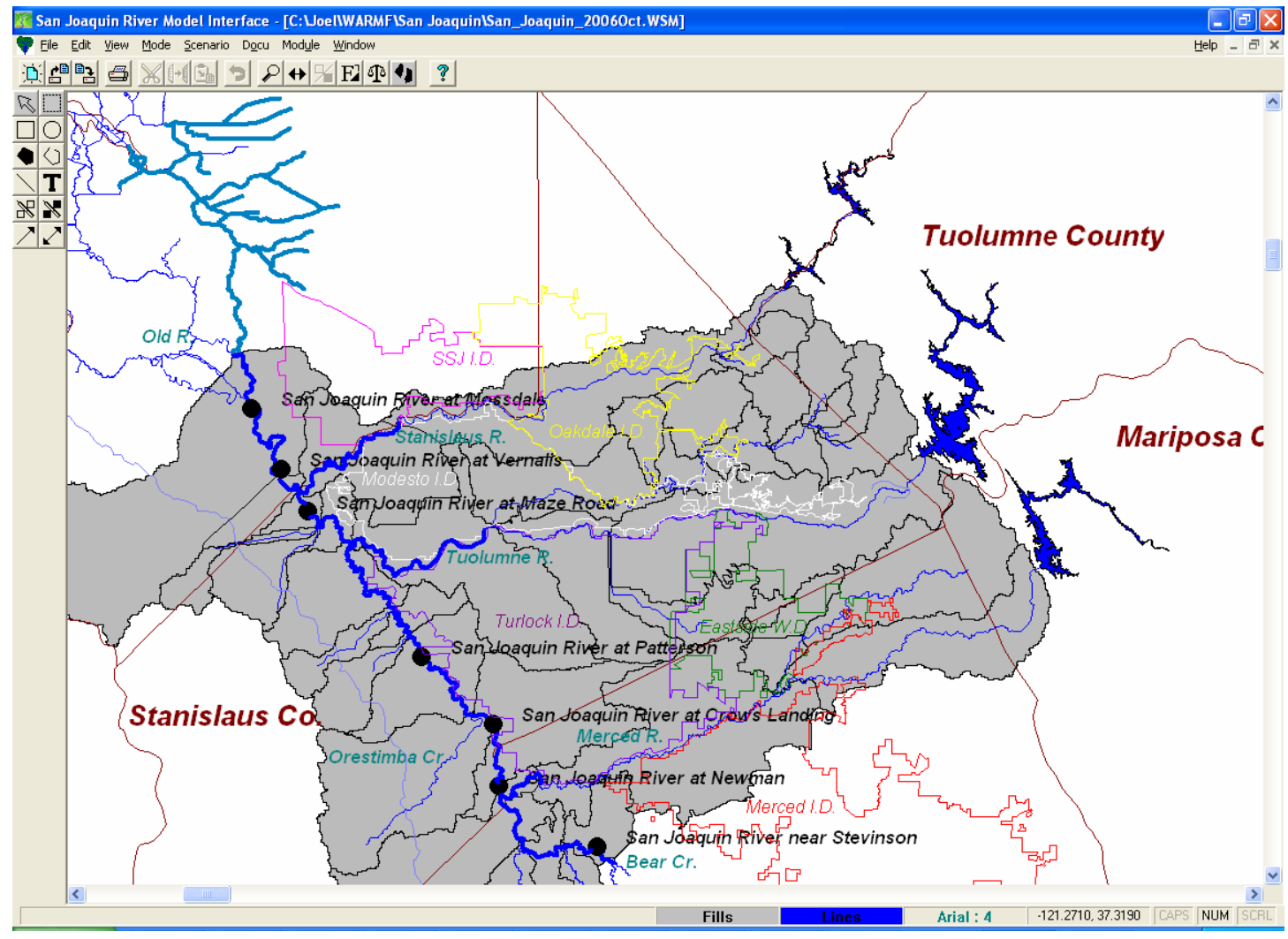

Figure 3. WARMF-SJR model application for the San Joaquin Basin (Herr, J., L. Weintraub, and C.W. Chen, 2000).

\section{Salinity and Nutrient Management Planning}

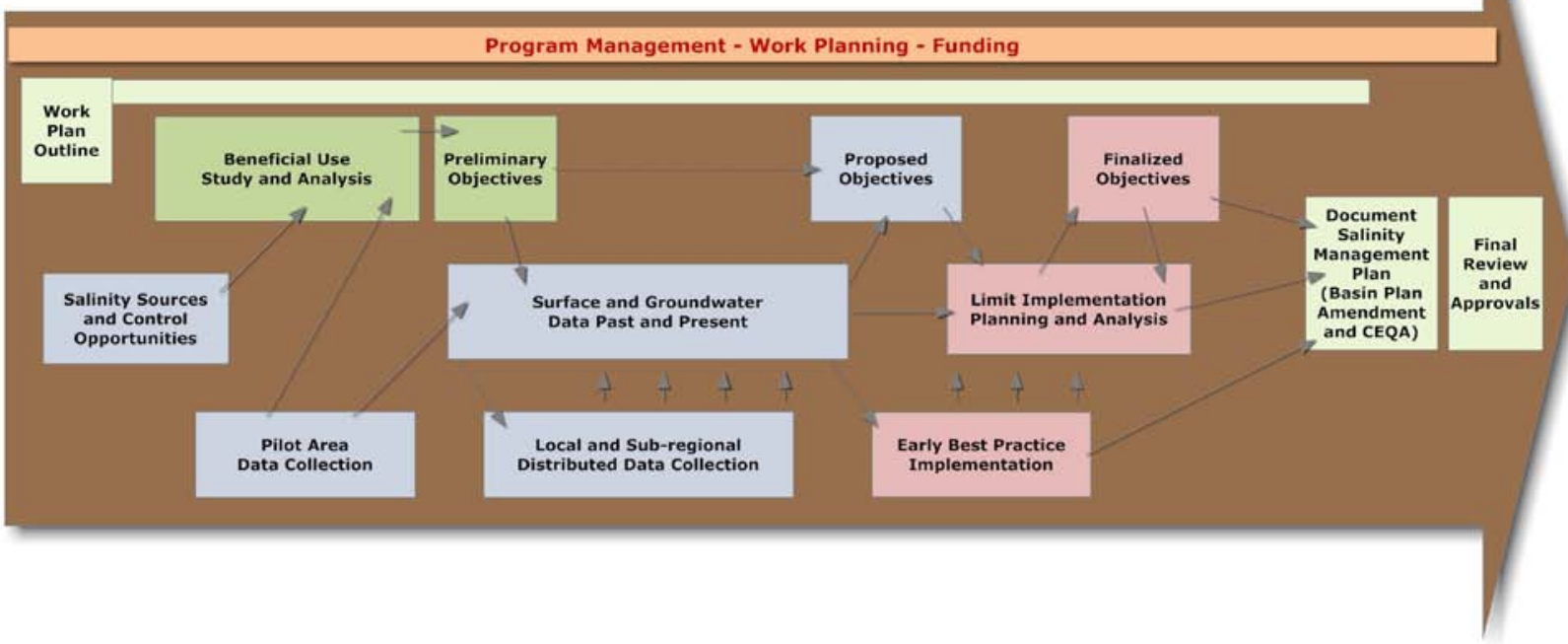

Figure 4. Central Valley Salinity Coalition planning process. The Coalition's goal is the revision of the State Basin Plan for salinity management in the Central Valley (http://www.cvsalinity.com). 


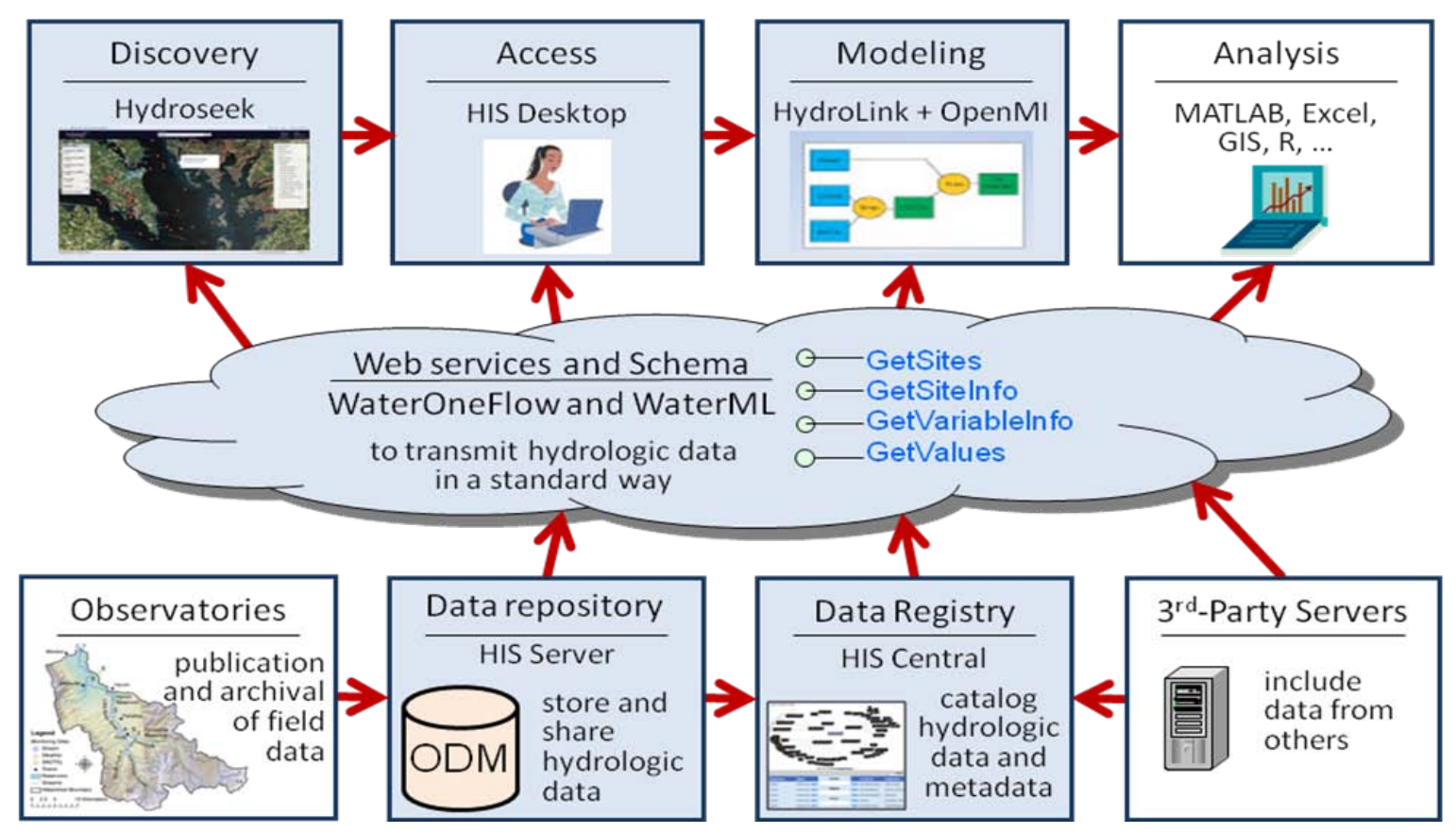

Figure 5. Conceptual system model with the CUAHSI Hydrologic Information System Water Data Services (Maidment, 2008; Tarboton, D.G., 2005). 